\title{
Introducing empirical and probabilistic regional envelope curves into a mixed bounded distribution function
}

\author{
B. Guse ${ }^{1,2, *}$, Th. Hofherr ${ }^{2,3,4}$, and B. Merz ${ }^{1}$ \\ ${ }^{1}$ Deutsches GeoForschungsZentrum Potsdam GFZ, Section 5.4 - Hydrology, Telegrafenberg, 14473 Potsdam, Germany \\ ${ }^{2}$ Center for Disaster Management and Risk Reduction Technology (CEDIM), 76187 Karlsruhe, Germany \\ ${ }^{3}$ Institute for Meteorology and Climate Research, Karlsruhe Institute of Technology (KIT), 76128 Karlsruhe, Germany \\ ${ }^{4}$ Geo Risks Research, Münchener Rückversicherungs-Gesellschaft, 80791 Munich, Germany \\ *now at: Department of Hydrology and Water Resources Management, Christian-Albrechts-Universität zu Kiel, \\ Olshausenstrasse 40, 24098 Kiel, Germany
}

Received: 3 June 2010 - Published in Hydrol. Earth Syst. Sci. Discuss.: 6 July 2010

Revised: 3 November 2010 - Accepted: 16 November 2010 - Published: 9 December 2010

\begin{abstract}
A novel approach to consider additional spatial information in flood frequency analyses, especially for the estimation of discharges with recurrence intervals larger than 100 years, is presented. For this purpose, large flood quantiles, i.e. pairs of a discharge and its corresponding recurrence interval, as well as an upper bound discharge, are combined within a mixed bounded distribution function. The large flood quantiles are derived using probabilistic regional envelope curves (PRECs) for all sites of a pooling group. These PREC flood quantiles are introduced into an at-site flood frequency analysis by assuming that they are representative for the range of recurrence intervals which is covered by PREC flood quantiles. For recurrence intervals above a certain inflection point, a Generalised Extreme Value (GEV) distribution function with a positive shape parameter is used. This GEV asymptotically approaches an upper bound derived from an empirical envelope curve. The resulting mixed distribution function is composed of two distribution functions which are connected at the inflection point.

This method is applied to 83 streamflow gauges in Saxony/Germany. Our analysis illustrates that the presented mixed bounded distribution function adequately considers PREC flood quantiles as well as an upper bound discharge. The introduction of both into an at-site flood frequency analysis improves the quantile estimation. A sensitivity analysis reveals that, for the target recurrence interval of 1000
\end{abstract}

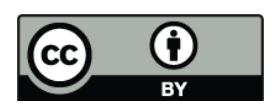

Correspondence to: B. Guse (bguse@hydrology.uni-kiel.de) years, the flood quantile estimation is less sensitive to the selection of an empirical envelope curve than to the selection of PREC discharges and of the inflection point between the mixed bounded distribution function.

\section{Introduction}

Flood frequency analysis provides flood quantiles, i.e. discharges and their corresponding recurrence intervals. Especially for recurrence intervals $T>100$ years, flood quantile estimates are very uncertain, due to the limited length of the measured flood series and the low number of representative data for extreme floods (e.g. Cohn and Stedinger, 1987; Merz and Thieken, 2005; Reis Jr. and Stedinger, 2005).

To reduce the estimation uncertainty of an at-site flood frequency analysis, it is recommended to use more information than the observed flood series (e.g. Hosking and Wallis, 1986a; Stedinger and Cohn, 1986; Merz and Blöschl, 2008a,b; Merz and Thieken, 2009). Since the quantile estimates become less precise with higher recurrence intervals, additional information becomes increasingly important in these cases (e.g. Hosking and Wallis, 1986a). Additional information can be classified into three groups: causal, temporal (historic floods) and spatial (flood regionalisation) information (Merz and Blöschl, 2008a,b). First, process understanding can be incorporated as causal information into a flood frequency analysis. For example, Merz and Blöschl (2008a) illustrated that an investigation of event runoff coefficients helps to explain the generation processes

Published by Copernicus Publications on behalf of the European Geosciences Union. 
of extreme floods and therefore to describe the upper tail behaviour of a distribution function.

Second, systematic time series can be extended by integrating historic floods as non-systematic data (Stedinger and Cohn, 1986). These historic extreme floods lead to more data for the estimation of large quantiles (e.g. England Jr. et al., 2003b; Benito et al., 2004). Historic observations contain considerable measurement errors, but due to the short systematic observation period, such additional information is useful (e.g. Hosking and Wallis, 1986b), and an increase of the effective record length leads to a better estimation of flood quantiles (Condie and Lee, 1982; Stedinger and Cohn, 1986; Cohn and Stedinger, 1987).

Third, flood regionalisation aims at improving flood quantile estimates by using information from gauges with similar hydrologic characteristics. In this way, the limited length of flood series is compensated by using regional flood series, following the principle of "trading space for time" (Stedinger et al., 1993). Gutknecht et al. (2006) proposed to combine local and regional methods within a "multi-pillar"-approach to reduce the uncertainty of flood quantile estimates for large recurrence intervals.

The selection of a distribution function which is suitable to estimate extreme floods is difficult (e.g. Merz and Thieken, 2005; El Adlouni et al., 2008). Parameter estimation methods mostly concentrate on the central parts of the distribution function. The upper tail which is the most relevant for extreme flood events and is subject to the largest uncertainty is often not adequately described (Moon et al., 1993). Hence, for the estimation of large flood quantiles, it is recommended to concentrate on extreme floods and to derive as much information as possible from them (Naghettini et al., 1996).

Hydrological characteristics, e.g. generation mechanisms of extreme floods, might be different compared to those of high-frequency floods (e.g. Chbab et al., 2006; Gutknecht et al., 2006; Merz and Blöschl, 2008b). Therefore, the use of a single distribution function to represent the flood behaviour across the complete spectrum of recurrence intervals is critical (England Jr. et al., 2003a), which is why mixed distribution functions are recommended. For instance, the twocomponent extreme value (TCEV) distribution (Rossi et al., 1984) includes two different distribution functions for normal and extreme events, respectively (e.g. Francés, 1998; Fernandes and Naghettini, 2008). The idea of mixed distribution functions is also the basis of the gradex approach (Guillot and Duband, 1967), in which the traditional flood frequency curve is used up to a recurrence interval, at which the corresponding discharge leads to catchment saturation. Above that threshold, the flood frequency curve follows the rainfall frequency curve, assuming that the rainfall records are longer and more precise than flood series (e.g. Naghettini et al., 1996; Gutknecht et al., 2006; Merz et al., 2008).

Traditional distribution functions with three parameters, such as the Generalised Extreme Value (GEV) or General Logistic (GL), are unbounded or only bounded in specific cases (e.g. GEV with a shape parameter $k>0$ ). This implies that the increase of the frequency curve is unlimited and that a non-zero exceedance probability for unrealistic large flood discharges is estimated (Enzel et al., 1993).

Distribution functions were developed which asymptotically approach an upper bound (e.g. the extreme value distribution with four parameters - EV4; Kanda, 1981; Francés and Botero, 2003). Francés and Botero (2003) combined non-systematic and systematic data with a bounded distribution function in their application of the EV4. The most critical aspect of distribution functions with an upper bound is the determination of the upper bound discharge.

Upper bound discharges can be derived, on the one hand, by estimating a probable maximum flood (PMF). To estimate a PMF, a probable maximum precipitation (PMP) is transformed into a PMF. Therefore, the most extreme meteorological and hydrological conditions for a given region are derived (e.g. Costa, 1987; Houghton-Carr, 1999; Fernandes et al., 2010). On the other hand, envelope curves provide upper bound discharges. Envelope curves bound all regional unit floods of record, i.e. the maximum unit flood discharges, by relating them to their catchment sizes. The method of empirical envelope curves (ECs) is a simple method which is not based on physical assumptions (Crippen, 1982). ECs are traditionally constructed for an administrative region (e.g. China and USA; Costa, 1987; Europe and the World; Herschy, 2002). Merz and Thieken (2009) enlarged the European data set of Stanescu (2002) by German floods of record from the last years and derived an EC which was used as additional information to constraint the selection of distribution functions.

Castellarin et al. (2005) and Castellarin (2007) extended the traditional method of envelope curves by presenting probabilistic regional envelope curves (PRECs). In this method, an exceedance probability is assigned to the regional envelope curve (REC). As a result, PRECs provide large flood quantiles, i.e. pairs consisting of a PREC discharge and its corresponding recurrence interval, i.e. the inverse of the exceedance probability, for each gauge of a homogeneous pooling group of sites. The assignment of a non-zero exceedance probability to the PREC discharge is the basis for including the PREC results into unbounded distribution functions.

This study aims at improving flood frequency estimates for large recurrence intervals $T$ by using additional information provided by empirical and probabilistic regional envelope curves. Since this study aims at integrating both, a distribution function needs to be selected which considers an upper bound discharge as well as large flood quantiles derived from PRECs. By doing so, for the first time, PREC flood quantiles are inserted into a flood frequency curve.

This study is structured as follows: in Sect. 2, study area, Saxony/Germany, and data are presented. The methods of empirical envelope curves and probabilistic regional envelope curves are briefly explained in Sect. 3 . Here, we also present the results of previous studies, in which PREC flood 


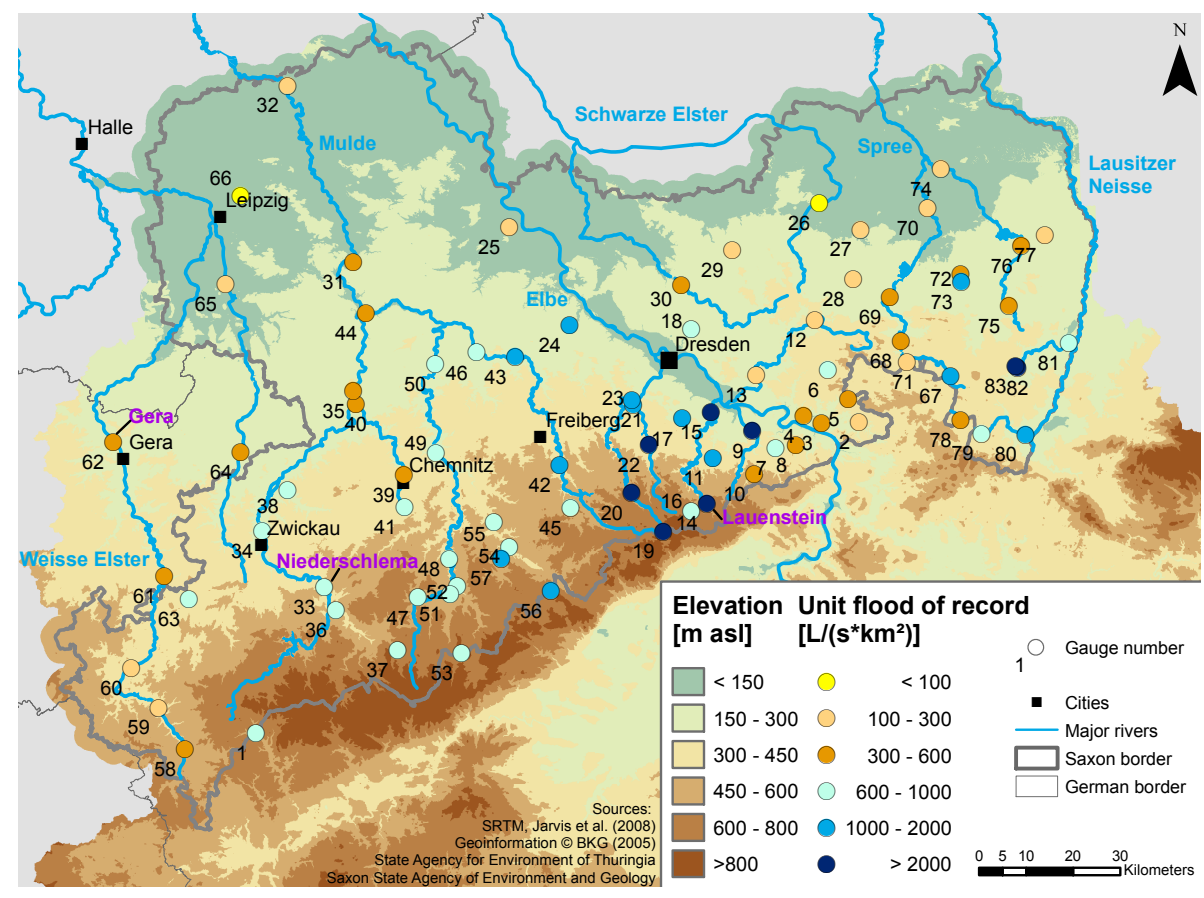

Fig. 1. Study region (Saxony/Germany) and selected discharge gauges coloured by their unit floods of record (modified from Guse et al., 2009). The three gauges which were used in the application (see Sect. 5) are named in purple.

quantiles were derived for Saxon gauges (Guse et al., 2009, 2010). The novel method to improve the flood frequency estimates is described in Sect. 4. It is explained how large flood quantiles and an upper bound discharge can be introduced into a suitable distribution function. In Sect. 5, we show the results of our method and evaluate the sensitivity of relevant choices when estimating discharges with the presented mixed bounded distribution for a target $T$ of 1000 years.

\section{Study area and data}

The study area is the federal state of Saxony which is located in south-eastern Germany. The south-western part is covered by the mountain range of the Erzgebirge, which has the largest altitudes in Saxony (Fig. 1). The Elbe is the largest river in the investigation area.

The largest unit floods of record were observed at the western tributaries of the River Elbe coming from the Erzgebirge (e.g. gauges 9 and 15 in Fig. 1) and at a tributary of the Lausitzer Neisse (gauges 82 and 83). In the observation period, both local and regional floods are included which affected in particular the Erzgebirge (Pohl, 2004). Extreme floods in Saxony belong to two flood types: small tributaries in the mountain range of the Erzgebirge are affected by flash floods, while riverine floods along the River Elbe are characterised by a slow rise of the water level (Ulbrich et al., 2003; Petrow et al., 2006). An extreme event in 2002 led to severe flood damages at almost all tributaries originating in the Erzgebirge and along the rivers Elbe and Mulde (e.g. Ulbrich et al., 2003; Thieken et al., 2005). Particularly due to this flood, several Saxon flood time series are very skewed (Petrow et al., 2007). The 2002 flood led to large modifications of the frequency curve and especially of the shape parameter at several gauges in Saxony (Schumann, 2004, 2005), and revealed the uncertainty of at-site flood frequency estimates without additional information. This confirmed the need for representative extreme events within the data series.

The discharge gauges are distributed along all relevant rivers and tributaries in the investigation area. We used 83 gauges, including two from Thuringia (gauges 61 and 62). We selected gauges with observation periods $>29$ years and catchment sizes $>10 \mathrm{~km}^{2}$ and without large effects due to mining activities or dams. The annual maxima series (AMS) as well as the maximum observed discharge, i.e. the flood of record, were derived for all 83 gauges.

\section{Envelope curves}

Two types of envelope curves were used as additional information for flood frequency analysis. First, upper bound discharges were derived from empirical envelope curves (ECs) and second, large flood quantiles were provided by probabilistic regional envelope curves (PRECs). Both methods are briefly introduced and the results of former PREC studies (Guse et al., 2009, 2010) are presented. 


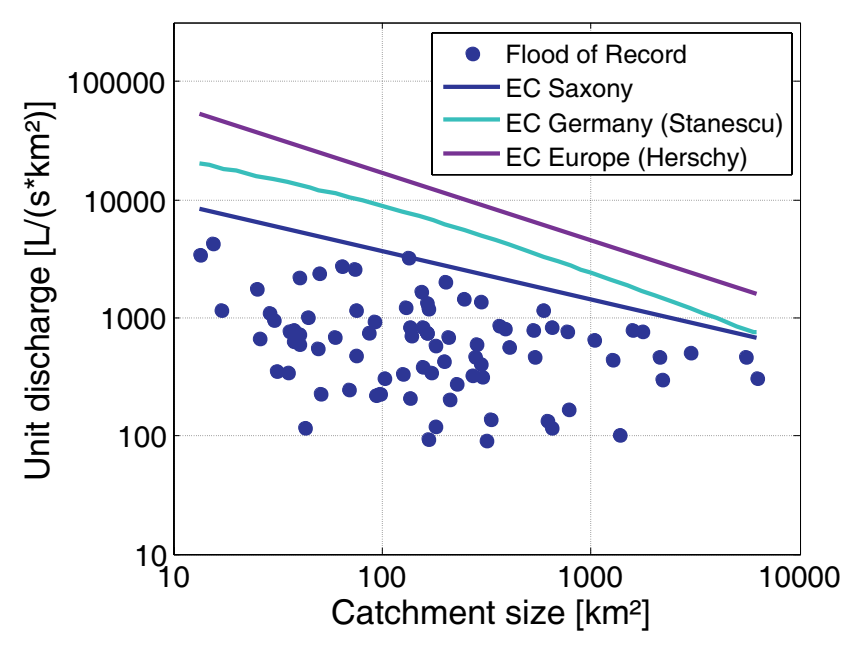

Fig. 2. Comparison of three different envelope curves. The floods of record of Saxon gauges are additionally shown.

Envelope curves are boundary lines above all observed floods of record of a region (see Figs. 2 and 3). Therefore, the floods of record $Q_{\mathrm{FOR}}$ are normalised by their catchment size $A$ and then related to $A$ in a double-logarithmic plot. Envelope curves are determined by their slope $b$ and intercept $a$ (Eq. 1, adapted from Castellarin et al., 2005).

$\log \left(\frac{Q_{\mathrm{FOR}}}{A}\right)=a+b \cdot \log (A)$

\subsection{Empirical envelope curves}

In this study, an upper bound with an exceedance probability of zero for Saxony needs to be estimated, since this upper bound discharge is used as an input for a distribution function with upper bound. Three empirical envelope curves were constructed (Fig. 2) and checked for their suitability as upper bound discharge for Saxon gauges. First, an envelope curve based on the Saxon floods of record only was derived. Second, the envelope curve for Germany $\mathrm{EC}_{\mathrm{G}}$ from Stanescu (2002) was selected. Third, the European envelope curve $\mathrm{EC}_{\mathrm{E}}$ of Herschy (2002) was used.

The Saxon envelope curve was determined by the largest unit flood of record in Saxony. The floods of record of several gauges are close to this EC. Thus, it is inconsistent to assume that the Saxon envelope curve has an exceedance probability of zero with respect to $T_{\text {PREC }}$ between 150 and 1500 years which were estimated by PRECs for this study region in Guse et al. (2009) (see Sect. 3.4). For a few gauging stations, the discharges provided from PRECs were close to or even larger than the Stanescu envelope curve for Germany. Since it was advisable to take an envelope curve which is certain to be the upper bound of Saxon flood discharges, we used the European envelope curve by Herschy (2002). This envelope curve is expected to be an upper bound which might not be exceeded in Saxony, since it is determined by

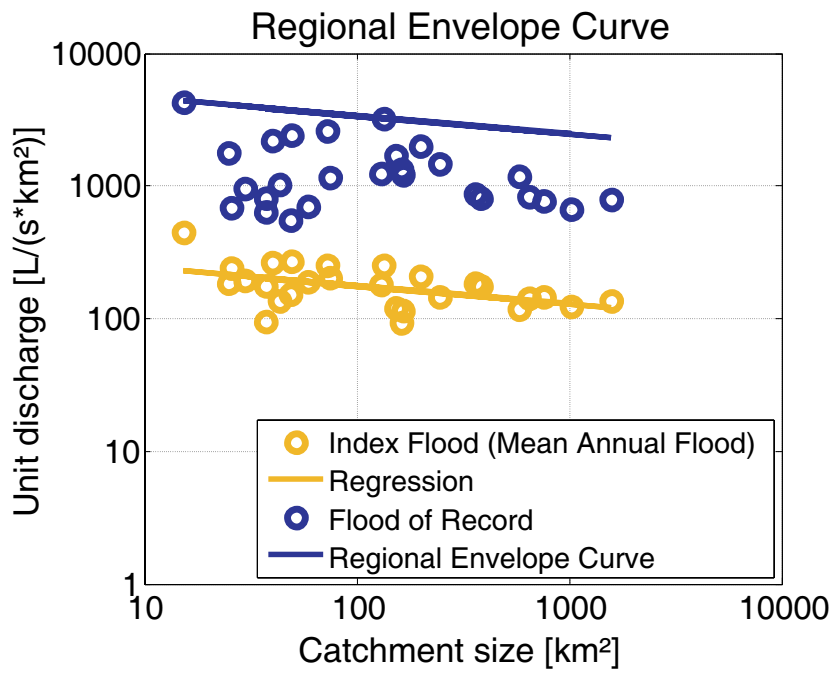

Fig. 3. Example of Regional Envelope Curve (REC) (from Guse et al., 2010).

significantly larger floods from the Mediterranean region. Stanescu (2002) and recently Gaume et al. (2009) compared ECs of European countries and determined the largest magnitude for Mediterranean countries. Stanescu (2002) concluded that larger floods are possible around the Mediterranean Sea than in Central European countries, owing to the higher temperature and larger humidity contained in the air masses. The Stanescu envelope curve was used only to investigate the sensitivity of the selection of the empirical envelope curve (see Sect. 4.3).

\subsection{Probabilistic regional envelope curves}

For an accurate representation of the upper tail of the distribution function and, in particular, of discharges with recurrence intervals in the order of 1000 years, probabilistic regional envelope curves (PRECs) (Castellarin et al., 2005; Castellarin, 2007) were used. The core idea of the PREC concept is the estimation of an exceedance probability for a regional envelope curve (REC) based on two hypotheses. First, PRECs can be only derived for homogeneous regions as indicated in the index flood method (Dalrymple, 1960; Robson and Reed, 1999). The index flood method assumes regional homogeneity for sites with similar higher moments. We used the mean of the annual maxima series as index flood. The second hypothesis is the scaling of the index flood with the catchment size. The methodical aspects of the PREC concept which are relevant for this study are presented as follows.

The slope $b$ of REC (Eq. 1) can be determined by a regression through all index flood values of the pooling group (Fig. 3). In addition, the floods of record of all sites of the homogeneous region are shown. The intercept a of REC is estimated by shifting the regression line up to the largest standardised flood of record (i.e. the flood of record divided by 
the index flood of the given site). Hence, the intercept a is determined by the largest standardised flood of record in the pooling group (Castellarin et al., 2005).

To estimate the recurrence interval of REC, the overall sample years of the annual maxima series (AMS) of all sites of a given homogeneous region are selected. To consider the real information content of the data, the effective sample years of data are calculated. In this way, the reduction of the regional information content of the data due to cross-correlated and concurrent flood sequences is considered. Castellarin (2007) presented an empirical relationship for this case which considers the intersite dependence among the AMS. For a detailed description of this relationship, we refer to Castellarin (2007) and Guse et al. $(2009,2010)$. The recurrence interval $T$ of REC is then estimated by using the Hazen plotting position and the number of effective sample years of data $n_{\text {eff }}$ (Eq. 2; from Castellarin, 2007)

$T=2 \cdot n_{\mathrm{eff}}$

The recurrence interval is calculated for the pair of the standardised flood of record and its corresponding catchment size, which governs the REC (Castellarin, 2007). The PREC provides a discharge $Q_{\text {PREC }}$ for each gauge of the pooling group with the same recurrence interval $T_{\mathrm{PREC}}$.

\subsection{Application of probabilistic regional envelope curves in Saxony}

In previous studies, several PRECs were derived for Saxony (Guse et al., 2009, 2010). A major step in the PREC concept is the determination of the pooling group of sites. Guse et al. (2010) used cluster analysis and the Region of Influence (RoI) approach (Burn, 1990) to construct several pooling groups using twenty candidate sets of two or three catchment descriptors and different settings of the two pooling methods. An own PREC was constructed for each pooling group, which fulfils the homogeneity criteria of the heterogeneity measure $\left(H_{1}<2\right)$ of Hosking and Wallis (1993). Hence, the constitution of the homogeneous regions and thus PRECs differed depending on the grouping procedure.

Guse et al. (2010) estimated the performance of each PREC application by comparing the PREC method with the index flood method. Therefore, the PREC flood quantiles were estimated for ungauged conditions using a crossvalidation procedure (Castellarin, 2007; Castellarin et al., 2007; Guse et al., 2010). The relative error between PREC discharge and the index flood discharge for the recurrence interval of PREC was calculated (Guse et al., 2010). A high relative error was estimated for sites with a significantly smaller flood of record than the $Q_{\text {PREC }}$ estimates for this site (see Fig. 7 in Guse et al., 2010). PREC realisations with a low performance error give better additional information than those with a larger one. The flood quantile estimation would not gain by the inclusion of PREC flood quantiles with a high performance error. Hence, PREC flood quantiles with a relative error $<2$ were used in this study only. By doing so, PREC realisations that deviated strongly from the index flood method were not considered. This means that PREC flood quantiles of a site, which were more than three times larger for ungauged conditions than the index flood estimates for the same $T_{\text {PREC }}$, were excluded.

The number of PREC realisations varied among the gauges between 0 and 127. A site had a lower number of PREC flood quantiles when it belonged more often to heterogeneous regions due to the specific characteristics of this gauge. Of the 89 gauges available in the previous studies, only the 83 gauges with at least one PREC realisation were used for this study (see Fig. 1). In the previous study, $T_{\text {PREC }}$ varied between 150 and 1500 years with a mean value of 650 years (Guse et al., 2009).

\subsection{Comparison of empirical and probabilistic regional envelope curves}

When comparing the traditional empirical envelope curves with the probabilistic regional envelope curves, one has to take note of the differences between the two approaches. In addition to the description of both methods in Sects. 3.1 and 3.2, here we present differences which are relevant for the application in the study region.

Several studies have presented the slope values of empirical envelope curves. On average, a slope of -0.5 is estimated with values between -0.2 and -0.7 (e.g. Herschy, 2002; Castellarin et al., 2005; Castellarin, 2007; Gaume et al., 2009). In our study, the slopes of the empirical envelope curves are close to -0.4 . In contrast, the slope of the PREC realisations in Saxony has a lower negative value in the majority of the cases. Here, the slope $b$ is about -0.2 . This means that the effect of the catchment size is smaller.

Since the intercept of the empirical envelope curve is larger than those of the PREC realisations in this study, it follows that the discharge of EC is larger than in the PREC concept. This result is understandable given that we assume in this study that the EC has an exceedance probability of zero, while that of the PREC lies between $6.7 \times 10^{-4}$ and $6.7 \times 10^{-3}$ (the inverse values of 150 and 1500 , respectively) for this study region (see Guse et al., 2009).

The slopes of the PRECs are in the majority of the cases smaller than those of the ECs. Hence, PRECs approach the ECs with increasing catchment size. Since the PREC discharges should be lower than the upper bound discharge from EC in all cases, the consistency of PREC discharges was checked for all sites of each PREC realisation. PREC discharges which were larger than the upper bound derived by the Stanescu envelope curve were removed. These cases were detected for sites with a large catchment size. For these sites, we used the PREC flood quantiles with discharges smaller than the Stanescu EC. Whereas the Stanescu EC is based on a large number of sites from Germany, the number of sites in the PREC approach varied depending on the 
grouping procedure and as it is shown in Fig. 2 the available number of sites with large catchment sizes was rather low for the PREC applications. It is assumed that the estimation of the empirical envelope curve was better than those of PREC in these cases with a large catchment size. In this way, consistency among both methods was ensured.

\section{Methods}

This study aims at inserting large flood quantiles and upper bound discharges as additional information into a distribution function to improve the flood quantile estimates for $T>100$ years. For this purpose, a distribution function is requested, into which large flood quantiles derived by PRECs, i.e. $Q_{\mathrm{PREC}}$ and corresponding $T_{\mathrm{PREC}}$, as well as an upper bound discharge $Q_{\mathrm{MAX}}$, provided by an empirical envelope curve, can be integrated. The method consists of two steps:

1. Integration of the PREC flood quantiles into the observed flood series (Sect. 4.1)

2. Application of a mixed bounded distribution function including PREC flood quantiles and an empirical envelope curve discharge as upper bound (Sect. 4.2)

Figure 4 gives an overview about our approach, including the most relevant variables. The core idea is an improvement of discharge estimates for a target recurrence interval $T_{\mathrm{t}}$ of 1000 years (orange line in Fig. 4). As additional information, PREC flood quantiles with recurrence intervals between 150 (lower value $T_{1}$ ) and 1500 (upper value $T_{\mathrm{u}}$ ) years are used (dashed cyan lines) and combined with the observed flood series in a distribution function $\left(\mathrm{GEV}_{\text {sim-prec }}\right)$. As second additional information, an upper bound discharge ( $\left.Q_{\mathrm{MAX}}\right)$ (purple line) derived from an empirical envelope curve is integrated into a distribution function. The resulting mixed bounded distribution $\left(\mathrm{GEV}_{\text {bound }}\right)$ consists of two distribution functions, connected at the inflection point $\left(T_{\mathrm{X}}\right)$ (dashed magenta line) and approaching the upper bound ( $\left.Q_{\mathrm{MAX}}\right)$ asymptotically. The mixed distribution function is identical with $\mathrm{GEV}_{\text {sim-prec }}$ up to the inflection point. From this point on, the bounded GEV is used.

\subsection{Integration of PREC flood quantiles}

In the first step, PREC flood quantiles were combined with the observed AMS. In a traditional regional flood frequency analysis, flood data from the site itself and from neighbouring sites are available. Since a PREC flood quantile comprises of a $Q_{\text {PREC }}$ and its corresponding $T_{\text {PREC }}$, it was impossible to add a $Q_{\text {PREC }}$ value directly to the AMS as one additional flood value. The additional information of the corresponding $T_{\text {PREC }}$ needs to be considered to use the complete information from PRECs. Hence, a novel method was developed. Its steps are illustrated in Fig. 5.

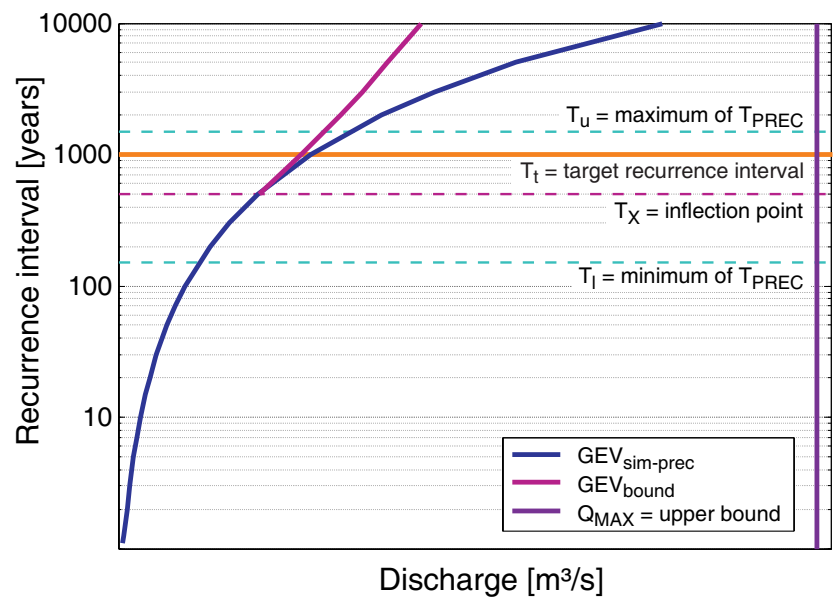

Fig. 4. Scheme of the proposed method including the most relevant variable names. The upper bound is illustrated in purple right of the legend. $\mathrm{GEV}_{\text {sim-prec }}$ is the combined distribution function of the observed flood series and the PREC flood quantiles. $\mathrm{GEV}_{\text {bound }}$ is a bounded distribution function which includes PREC flood quantiles as well as an upper bound discharge.

The Generalised Extreme Value (GEV) distribution was fitted to the observed AMS of each gauge using L-moments (Hosking and Wallis, 1997), denoted as GEV obs. The adequacy of the GEV for the flood series in this study was proven by L-moment ratio diagrams (see e.g. Vogel and Fennessey, 1993; Peel et al., 2001).

The three at-site $\mathrm{GEV}_{\text {obs }}$ parameters $(\xi, \alpha, k)$ were used to generate synthetic flood series. For this, $T_{\mathrm{u}}$ random numbers between 0 and $1\left(p_{\mathrm{sim}}\right)$ were generated. $T_{\mathrm{u}}$ was selected, since it was the maximum of $T_{\text {PREC }}$ for the study region. These $p_{\text {sim }}$ values were inserted into the GEV (Eq. 3) resulting in $T_{\mathrm{u}}$ simulated discharge values, denoted as $Q$.

$Q=\xi+\frac{\alpha}{k} \cdot\left[1-\left(-\ln \left(p_{\text {sim }}\right)\right)^{k}\right]$ with $k \neq 0$

Subsequently, the GEV was fitted to $Q$, denoted as $\mathrm{GEV}_{\text {sim }}$ with a new parameter set $\left(\xi_{\text {sim }}, \alpha_{\text {sim }}, k_{\text {sim }}\right)$.

To ensure consistency between $\mathrm{GEV}_{\text {sim }}$ and $\mathrm{GEV}_{\mathrm{obs}}$, the two should not differ considerably. For this, the flood quantiles for $T=T_{\mathrm{u}}$ years of both GEV functions were compared. It was decided that the discharge estimates of both functions should not vary more than $1 \%$ for $T_{\mathrm{u}}$. Otherwise, the random selection of $p_{\text {sim }}$ and the estimation of $Q$ were repeated.

A second constraint was that there had to be nine or ten values, denoted as $n_{x}$, larger than $p_{\mathrm{E}}=0.9933\left(=1-\frac{1}{150}\right)$. This value was selected, because the $T_{\mathrm{PREC}}$ values were larger than 150 years $\left(T_{1}=150\right)$. It was therefore assumed that the PREC flood quantiles were representative for $T>T_{1}$ years. A binomial function showed that the largest probability was estimated when assuming that nine or ten floods with $T>T_{1}$ were expected to occur within $T_{\mathrm{u}}$ years. This constraint was considered to prevent an influence of a randomly 


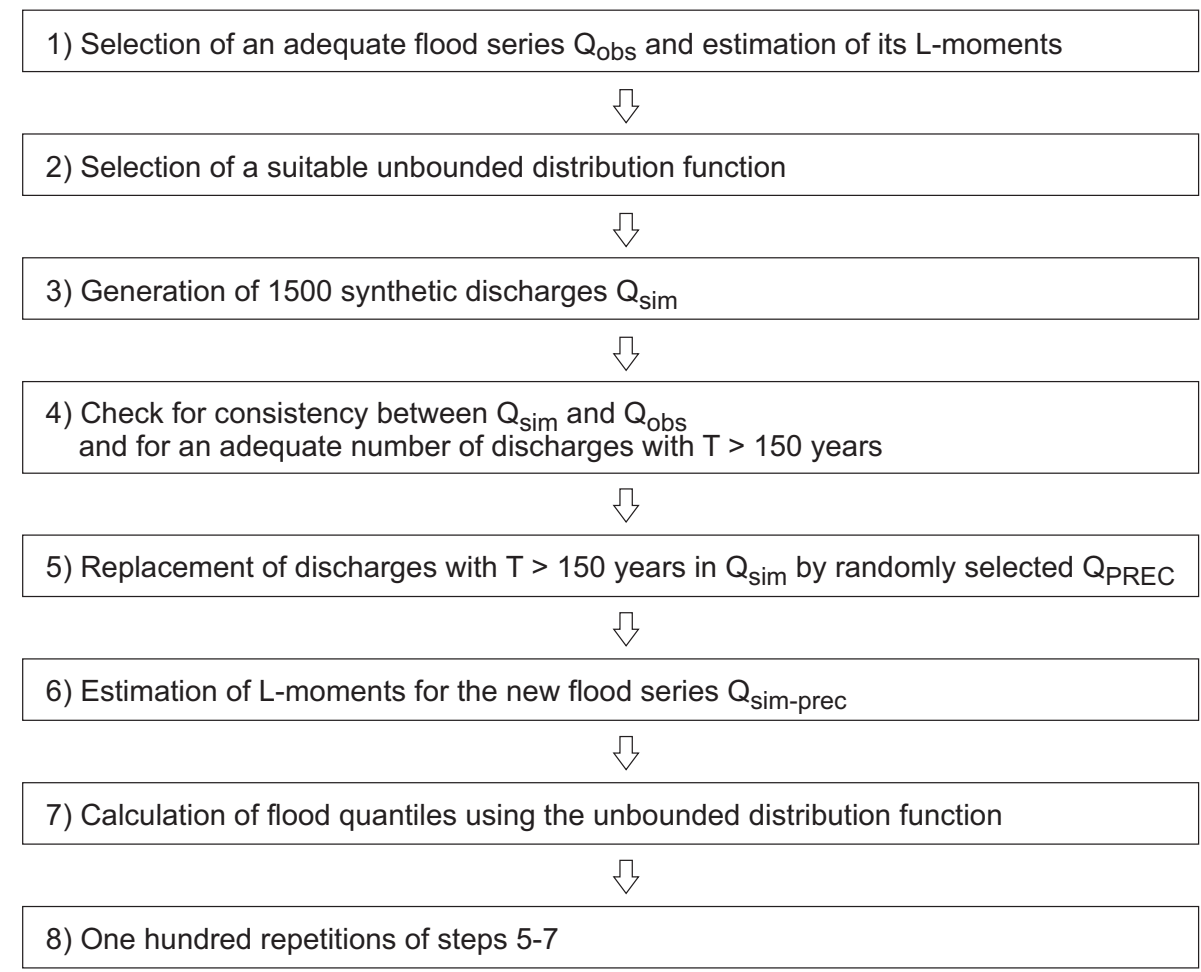

Fig. 5. Overview of the consecutive steps to integrate PREC flood quantiles into the at-site distribution function.

selected number of PREC flood quantiles. Then, $\mathrm{GEV}_{\text {sim }}$ and $\mathrm{GEV}_{\text {obs }}$ were assumed as sufficiently similar for using the $T_{\mathrm{u}}$ simulated flood series instead of the shorter measured time series.

In a next step, PREC flood quantiles were integrated into the simulated flood series $Q_{\text {sim. }}$. Among the random numbers $p_{\text {sim }}$, the $n_{x}$ values larger than $p_{\mathrm{E}}$ were removed from the simulated flood series $Q_{\text {sim }}$ and replaced by $n_{x} Q_{\text {PREC }}$ values. This approach implicitly assumes that the observed flood series is appropriate up to $T_{1}$. However, the PREC discharges also influenced the combined function of observed and PREC discharges for $T<T_{1}$.

Since previous studies provided more than $n_{x}$ PREC flood quantiles for most of the gauges (see Sect. 3.3) (Guse et al., 2010), $n_{x}$ PREC flood quantiles among the PREC realisations of a given gauge were selected in a random process whereas the discharges were weighted according to their $T_{\text {PREC }}$. We considered the recurrence intervals using a binomial function $B$ (Eq. 4). This approach was used to estimate the mean occurrence of a specific $Q_{\mathrm{PREC}}$ with a recurrence interval $T_{\text {PREC }}$ within $T_{\mathrm{u}}$ years.

$P(X=m)=B_{\mathrm{T}_{\mathrm{u}}} ; \frac{1}{T_{\mathrm{PREC}}}(X=m)$ with $m=1,2, \ldots, 20$

We checked $\mathrm{m}$ for one to twenty occurrences. Among these twenty results, we selected the $\mathrm{m}$ with the largest probability $P_{\max }$, i.e. the maximum likelihood, denoted as $m_{\max }$. The $Q_{\text {PREC }}$ value of this PREC realisation was assigned $m_{\max }$ times to a vector $V_{\text {PREC }}$. This implies that PREC discharges with a smaller $T$ were assigned more often to $V_{\text {PREC }}$. In this way, the recurrence interval of the PREC realisations was evidently considered, since a PREC flood quantile with a smaller $T_{\text {PREC }}$ was expected to occur more often than a PREC flood quantile with a larger one. This procedure was repeated for all PREC realisations of this gauge.

The $n_{x} Q_{\text {PREC }}$ values were then randomly selected without replacement from $\boldsymbol{V}_{\text {PREC }}$. In order to adequately represent $T_{\text {PREC }}$, a specific $Q_{\text {PREC }}$ could be selected as many times as it was included in $\boldsymbol{V}_{\text {PRECC }}$. The $n_{x}$ discharges derived from PREC were assigned to the reduced simulated flood series of $T_{\mathrm{u}}-n_{x}$ values, so that the new flood series comprised $T_{\mathrm{u}}$ values again.

In the majority of cases, the length of $\boldsymbol{V}_{\text {PREC }}$ was larger than $n_{x}$, which required the random selection of PREC discharges. In the other cases, for sites with a lower number of PREC realisations in $\boldsymbol{V}_{\text {PREC }}$ than $n_{x}, n_{x}$ values were removed from the simulated flood series as well. Then all values from $V_{\text {PREC }}$ were added. In order to obtain $T_{\mathrm{u}}$ values again, the remaining discharges to $T_{\mathrm{u}}$ were selected randomly from the $n_{x}$ discharges with $T>T_{1}$ years.

The GEV was fitted to the new flood series, denoted as $\mathrm{GEV}_{\text {sim-prec}}$, using L-moments. This approach allowed an integration of PREC flood quantiles in flood frequency estimations. Due to the random process, there might be differences in the magnitude of the selected PREC discharges, 
and therefore also in the final distribution function. Hence, we repeated the selection of $Q_{\text {PREC }}$ one hundred times and estimated one hundred GEV parameter sets. The GEV parameter sets which estimated the median discharge for $T_{\mathrm{t}}=1000$ years were used for the next steps. The corresponding GEV distribution was denoted as $\mathrm{GEV}_{\text {sim-prec }} 50$. The influence of the PREC selection on the discharge estimates was expressed by showing the 5\%- and $95 \%$-quantiles of $\mathrm{GEV}_{\text {sim-prec }}$ for $T_{\mathrm{t}}$, denoted as $\mathrm{GEV}_{\text {sim-prec } 05}$ and $\mathrm{GEV}_{\text {sim-prec } 95}$, respectively. A comparison of $\mathrm{GEV}_{\text {sim-prec }}$ with $\mathrm{GEV}_{\text {sim }}$ illustrated the effect of using PREC flood quantiles as additional information.

\subsection{Mixed bounded distribution function}

We used a mixed bounded distribution function which was developed in storm research (Hofherr et al., 2008). The use of this distribution function enables us to integrate an upper bound discharge as further additional information besides of the PREC flood quantiles.

In this mixed bounded distribution function, flood quantiles up to a recurrence interval threshold of $T_{\mathrm{X}}$ (inflection point) are estimated by an unbounded distribution function (here: $\mathrm{GEV}_{\text {sim-prec }}$ with $k<0$ ), and quantiles above the inflection point $T_{\mathrm{X}}$ are estimated by a bounded distribution (here: $\mathrm{GEV}_{\text {bound }}$ ). $\mathrm{GEV}_{\text {sim-prec }}$ includes PREC discharges which are representative for $T$ between 150 and 1500 years. To adequately represent the PREC discharges, we selected an inflection point $T_{\mathrm{X}}=500$ years. The sensitivity of the method to the choice of this inflection point was analysed in Sect. 4.3.

$\mathrm{GEV}_{\text {bound }}$ has a positive shape parameter $k$ and, hence, asymptotically approaches an upper bound. The three parameters of $\mathrm{GEV}_{\text {bound }}\left(\xi_{\text {bound }}, \alpha_{\text {bound }}, k_{\text {bound }}\right)$ were determined with a numerical solution method by three constraints using Eqs. (5)-(7). First, the upper bound $Q_{\operatorname{MAX}}$ which was provided by an empirical envelope curve was inserted into the GEV upper bound function (Eq. 5).

$Q_{\text {MAX }}=\xi_{\text {bound }}+\frac{\alpha_{\text {bound }}}{k_{\text {bound }}}$

Second, both GEV functions ( $\left.\mathrm{GEV}_{\text {sim-prec }}, \mathrm{GEV}_{\text {bound }}\right)$ had to be identical at the inflection point to avoid inconsistencies. Therefore, both functions were equated at the inflection point (Eq. 6).

$\operatorname{GEV}_{\text {sim-prec }}\left(T=T_{x}\right)=\operatorname{GEV}_{\text {bound }}\left(T=T_{x}\right)$

The third constraint was that both GEV functions had the same slope at the inflection point. Therefore, their derivates were equated (Eq. 7).

$\operatorname{GEV}_{\text {sim-prec }}{ }^{\prime}\left(T=T_{x}\right)=\operatorname{GEV}_{\text {bound }}{ }^{\prime}\left(T=T_{x}\right)$

In the case of a successful solution, $\mathrm{GEV}_{\text {bound }}$ was fully defined, increasing monotonically.
The mixed bounded distribution function was not applied for the seven sites with a positive $k$ of $\mathrm{GEV}_{\text {sim-prec }}$. In these cases, the $\mathrm{GEV}_{\text {sim-prec }}$ was already bounded. Since they already approach an upper bound, even after integrating PREC discharges, the number of sites for which the mixed bounded distribution function was applied was reduced to 76 . The main advantage of a bounded distribution function is that it avoids an unlimited increase up to unrealistic discharge values, which was already prevented by the positive $k$ values in these cases. In this context, it is worth mentioning that ten sites have a positive $k$ for the at-site estimation. This means that the sign has been changed from positive to negative for three sites due to the inclusion of the PREC flood quantiles.

\subsection{Sensitivity analysis}

The effect of three choices in this method was investigated for a target recurrence interval $T_{\mathrm{t}}=1000$ years in a combined sensitivity analysis. The sensitivity of each choice was tested as follows:

1. The magnitude of the empirical envelope curve discharge: German EC $\left(\mathrm{EC}_{\mathrm{G}}\right)$ (Stanescu, 2002) vs. European $\mathrm{EC}\left(\mathrm{EC}_{\mathrm{E}}\right)$ (Herschy, 2002),

2. the selection of PREC discharges: $5 \%$ vs. $95 \%$ of the $\mathrm{GEV}_{\text {sim-prec }}$ estimates for $T_{\mathrm{t}}$,

3. and the magnitude of the recurrence interval threshold (inflection point): $T_{\mathrm{X}}=200 \mathrm{vs.} 500$ years.

For each choice, the four possible combinations of the two other choices were checked. The comparison of $Q_{\text {bound }}$ $\left(T_{\mathrm{t}}=1000\right)$ between all possible combinations of these three choices allowed us to evaluate their effect on the discharge estimations of $\mathrm{GEV}_{\text {bound }}$ for $T_{\mathrm{t}}$. The relative deviations are calculated for each choice (Eqs. 8-10). This procedure enabled us to determine the most sensitive choice of the discharge estimates for $T_{\mathrm{t}}$.

$$
\begin{aligned}
& E_{\mathrm{EC}}=\frac{Q_{\text {bound }}\left(Q_{\mathrm{MAX}}=\mathrm{EC}_{\mathrm{E}}\right)-Q_{\text {bound }}\left(Q_{\mathrm{MAX}}=\mathrm{EC}_{\mathrm{G}}\right)}{Q_{\text {bound }}\left(Q_{\mathrm{MAX}}=\mathrm{EC}_{\mathrm{G}}\right)} \\
& E_{\mathrm{PREC}}=\frac{Q_{\text {bound }}\left(\mathrm{GEV}_{\text {sim-prec }, 95}\right)-Q_{\text {bound }}\left(\mathrm{GEV}_{\text {sim-prec }, 5}\right)}{Q_{\text {bound }}\left(\mathrm{GEV}_{\text {sim-prec }, 5}\right)} \\
& E_{\mathrm{T}_{\mathrm{X}}}=\frac{Q_{\text {bound }}\left(T_{\mathrm{X}}=500\right)-Q_{\text {bound }}\left(T_{X}=200\right)}{Q_{\text {bound }}\left(T_{\mathrm{X}}=200\right)}
\end{aligned}
$$

\section{Results}

\subsection{Integration of PREC flood quantiles}

Figure 6 illustrates exemplarily for the gauge Lauenstein (site 14 in Fig. 1) that $\mathrm{GEV}_{\text {sim }}$ agrees well with $\mathrm{GEV}_{\text {obs }}$ (orange and black lines in Fig. 6). The blue-coloured circles symbolise the PREC discharges which were selected 


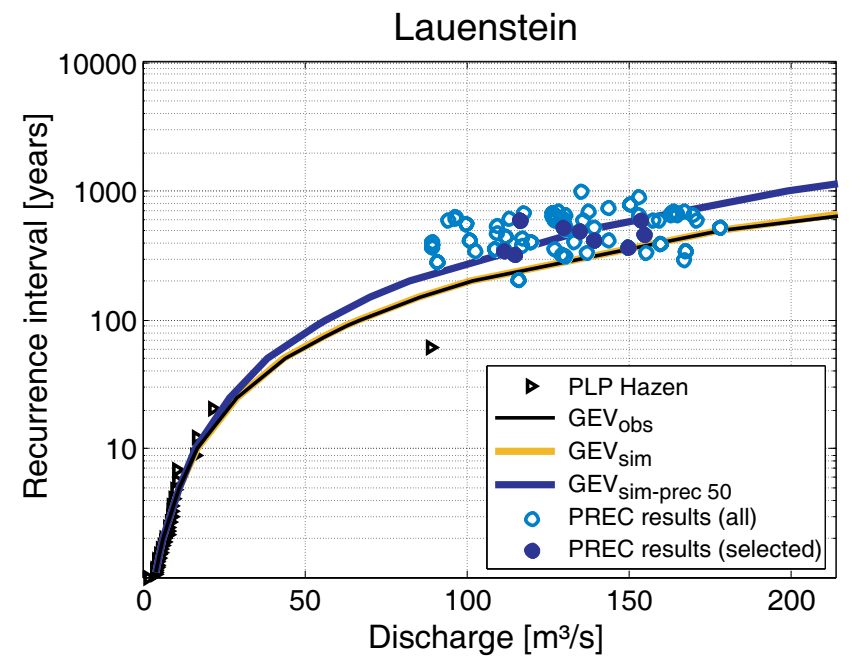

Fig. 6. Effect of integrating PREC flood quantiles into the at-site flood frequency analysis. $\mathrm{GEV}_{\text {obs }}, \mathrm{GEV}_{\text {sim }}$ and $\mathrm{GEV}_{\text {sim-prec }}$ are compared for the site Lauenstein. The observed flood series is illustrated as Hazen plotting position (PLP Hazen). The PREC flood quantiles which were selected for $\mathrm{GEV}_{\text {sim-prec } 50}$ are coloured in blue.

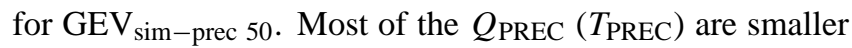
than the $Q_{\mathrm{GEV}}\left(T_{\mathrm{PREC}}\right)$. Hence, the integration of the PREC flood quantiles leads to a higher $k$ (shape parameter of GEV) and a lower skewness of $\mathrm{GEV}_{\text {sim-prec }}$ compared to $\mathrm{GEV}_{\text {sim }}$. Therefore, $Q_{\text {sim-prec }}$ for a given $T$ is smaller than $Q_{\text {sim }}$.

The PREC flood quantiles indicate that the skewness of the GEV might be too large when using the observed data only. The recurrence interval of the flood of record (flood discharge of 2002) might be larger than the at-site estimate. The effect of the flood of record on the estimation of large quantiles within the at-site flood frequency analysis seems to be too high. The smallest PREC discharge is identical with the flood of record of Lauenstein. This means that the intercept of this REC was determined by the at-site flood of record.

\subsection{Mixed bounded distribution function}

$\mathrm{GEV}_{\text {sim-prec }}$ was used to estimate the flood quantiles up to $T_{\mathrm{X}}=500$ years in the mixed bounded distribution approach. From $T_{\mathrm{X}}$ on, $\mathrm{GEV}_{\text {bound }}$ was used, which asymptotically approaches the upper bound discharge derived from the empirical envelope curve by Herschy (2002). Considering $\mathrm{GEV}_{\text {obs }}$ and $\mathrm{GEV}_{\text {bound }}$ for all gauges, three cases can be distinguished, which are shown in Fig. 7a-c. The variability due to the selection of PREC flood quantiles is demonstrated by adding the 5\%- and 95\%-quantiles (cyan dashed line).

In the first case (gauge Lauenstein, Fig. 7a), GEV bound estimates lower discharges than $\mathrm{GEV}_{\text {obs }}$ for all values of $T$. To give an example, $\mathrm{GEV}_{\text {bound }}$ estimates a discharge of $200 \mathrm{~m}^{3} / \mathrm{s}$ for $T_{\mathrm{t}}$, whereas the $\mathrm{GEV}_{\mathrm{obs}}$ discharge is about
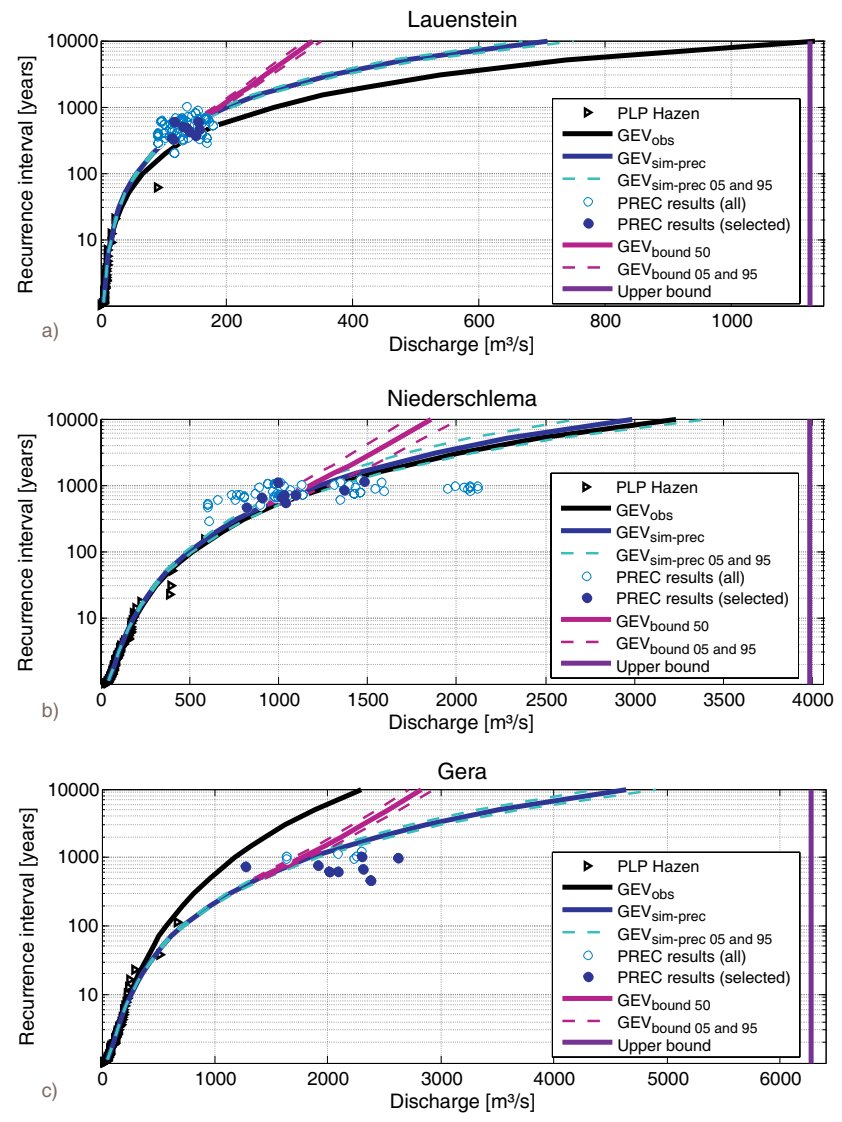

Fig. 7. The mixed bounded distribution function $G E V_{\text {bound }}$ vs. the traditional GEV $\left(\mathrm{GEV}_{\text {obs }}\right)$ and the $\mathrm{GEV}_{\text {sim-prec }}$ for the gauges (a) Lauenstein, (b) Niederschlema, (c) Gera. The blue-coloured PREC results show the selected PREC discharges which yielded a median discharge for the target recurrence interval of 1000 years among the hundred repetitions. The upper bound is illustrated in purple right of the legend.

$300 \mathrm{~m}^{3} / \mathrm{s}$. $\mathrm{GEV}_{\mathrm{obs}}$ increases unlimitedly, whereas the gradient of $\mathrm{GEV}_{\text {bound }}$ decreases and approaches the upper bound.

Figure $7 \mathrm{~b}$ shows an example (gauge Niederschlema, site 33 in Fig. 1) where several PREC discharges are larger than the $\mathrm{GEV}_{\text {obs }}$ discharge estimates for the same recurrence interval. However, there are also various smaller PREC flood quantiles. On average, $Q_{\mathrm{PREC}}\left(T_{\mathrm{PREC}}\right)$ is similar to $Q_{\mathrm{GEV}}$ ( $\left.T_{\text {PREC }}\right)$, and therefore $Q_{\text {sim-prec }}$ is similar to $Q_{\text {obss }}$. The PREC flood quantiles support the $\mathrm{GEV}_{\text {obs }}$ estimations, and the effect of the inclusion of PREC discharges is low.

In the third case, the PREC flood quantiles are larger than the $\mathrm{GEV}_{\mathrm{obs}}$ discharge estimates (gauge Gera in Fig. 7c, site 62 in Fig. 1). Here, $Q_{\text {bound }}$ is about 1.5 times larger than $Q_{\mathrm{obs}}$ for $T_{\mathrm{t}}$. Despite the asymptotical approach towards the upper bound, $Q_{\text {bound }}$ is larger than $Q_{\text {obs }}$ even for $T=10000$ years. There are gauges within the pooling groups of this site with significantly larger unit floods of record than those of Gera. The regional envelope curve has a considerably higher flood magnitude than the observed 


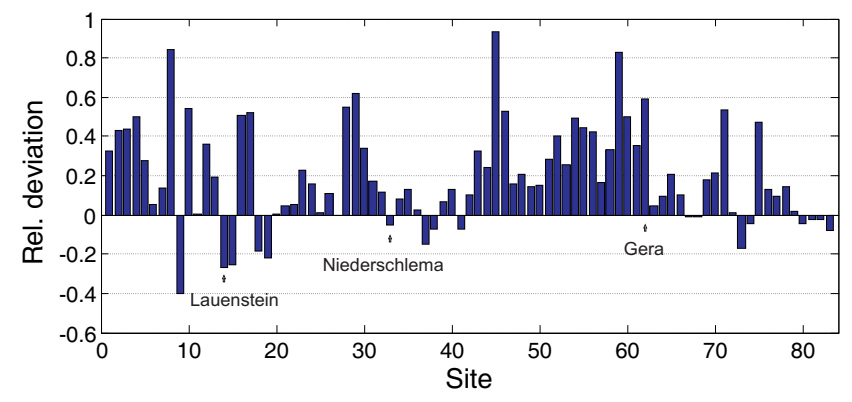

Fig. 8. Comparison of discharges estimated by $\mathrm{GEV}_{\text {sim }}$ and $\mathrm{GEV}_{\text {sim-prec } 50}$ for the target recurrence interval of 1000 years for 83 gauges. The three sites shown in Fig. 7 are marked.

discharges. The PREC flood quantiles indicate that a flood larger than the current flood of record might occur. The majority of the sites belongs to this third type.

\subsection{Comparison of the three distribution functions}

First, we compared $\mathrm{GEV}_{\text {sim }}$ and $\mathrm{GEV}_{\text {sim-prec }}$. After that, we examined the differences between $\mathrm{GEV}_{\text {sim }}$ and $\mathrm{GEV}_{\text {bound. }}$. In both cases, discharge estimates for $T_{\mathrm{t}}$ were compared by calculating the relative deviations and we used the median of the hundred GEV estimations for $\mathrm{GEV}_{\text {sim-prec }}$ and $\mathrm{GEV}_{\text {bound }}$.

The comparison of $\mathrm{GEV}_{\text {sim }}$ and $\mathrm{GEV}_{\text {sim-prec } 50}$ shows how strongly $\mathrm{GEV}_{\text {sim-prec } 50}$ is affected by PREC flood quantiles. Figure 8 illustrates that the relative deviation is positive in the majority of the cases. Hence, $\mathrm{GEV}_{\text {sim-prec }} 50$ estimates larger discharges than $\mathrm{GEV}_{\text {sim }}$ for almost all gauges. This result can be explained by the PREC flood quantiles. For the majority of the sites, the $Q_{\mathrm{PREC}}\left(T_{\mathrm{PREC}}\right)$ values are larger than the corresponding $Q_{\mathrm{GEV}}\left(T_{\mathrm{PREC}}\right)$ estimates. Hence, $\mathrm{GEV}_{\text {sim-prec } 50}$ also estimates larger values than GEV $_{\text {sim }}$ (see "Gera" type in Fig. 7c).

In a further step, $Q_{\text {sim }}$ and $Q_{\text {bound } 50}$ are compared (Fig. 9). A positive relative deviation indicates that $Q_{\text {bound }} 50$ is larger than $Q_{\text {sim }}$ despite the asymptotic behaviour towards the upper bound. The $Q_{\text {bound } 50}$ exceeds $Q_{\text {sim }}$, because $Q_{\text {PREC }}$ $\left(T_{\text {PREC }}\right)$ values are mostly larger in comparison to the corresponding $Q_{\mathrm{GEV}}\left(T_{\mathrm{PREC}}\right.$ ) (see example of Gera; Fig. 7c). This implies that the PREC discharges enormously affect the GEV and lead to larger discharges of $\mathrm{GEV}_{\text {bound }} 50$ than $\mathrm{GEV}_{\text {sim }}$ for the same recurrence interval. Figure $9 b$ shows that even for $T=10000$ years a positive relative deviation is estimated for the half of the sites. Due to the asymptotic behaviour of $\mathrm{GEV}_{\text {bound } 50}$, there are more sites with a negative relative deviation for $T=10000$ than for $T=1000$ years.

\subsection{Sensitivity analysis}

With a combined sensitivity analysis, the effect of the upper bound derived by the empirical envelope curve, of the $Q_{\text {PREC-selection and of the inflection point is investigated. }}$
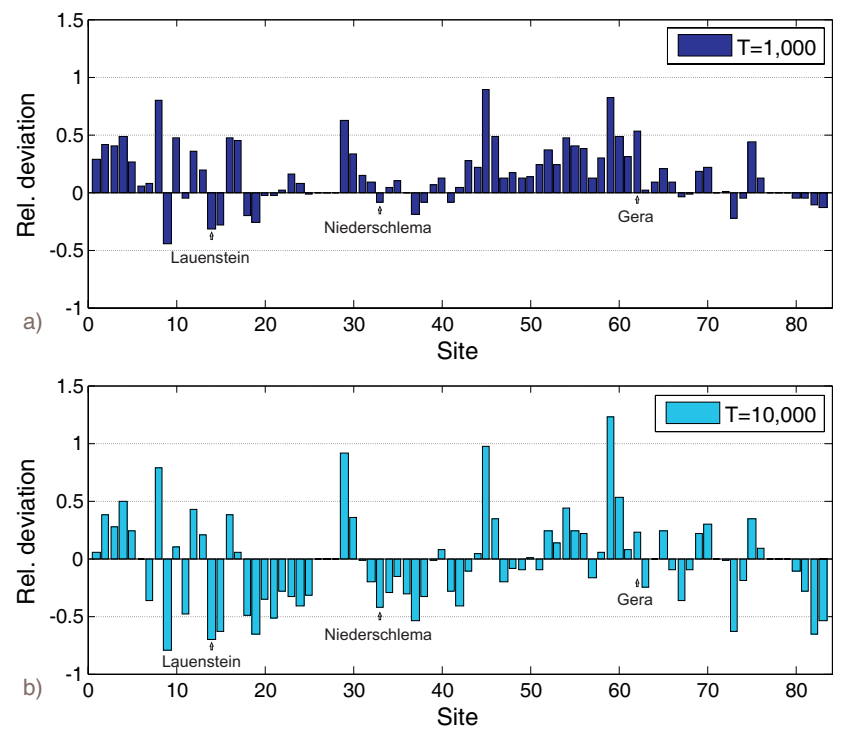

Fig. 9. Comparison of discharges estimated by $\mathrm{GEV}_{\text {sim }}$ and $\mathrm{GEV}_{\text {bound }} 50$ for recurrence intervals of (a) 1000 and (b) 10000 years. The three sites shown in Fig. 7 are marked. The seven sites with a positive $k$ are not shown.

Each sub-figure in Fig. 10 illustrates the results of one choice. The four possible combinations of the two other choices (see Sect. 4.3) are shown with four box-plots. Each box-plot is based on the results of the 76 sites. Figure 10a-c illustrate that the largest relative deviation is found when comparing the 5\%- and 95\%-quantiles of $\mathrm{GEV}_{\text {sim-prec }}$ and emphasise that it is necessary to consider different PREC selections. This variation occurs due to the random selection of the PREC discharges.

The selection of the empirical envelope curve has the lowest relative deviation. There are only small differences in Fig. 10a. Its effect is slightly larger for $T_{\mathrm{X}}=$ 200 years. The smaller $T_{\mathrm{X}}$, the smaller is the point at which $\mathrm{GEV}_{\text {bound }}$ asymptotically approaches to the upper bound and the stronger $\mathrm{GEV}_{\text {bound }}$ is influenced by the empirical envelope curve discharge.

The relative deviation due to the PREC selection is similar when varying the empirical envelope curve or the inflection point (Fig. 10b). Here, there is the inverse situation compared to the selection of the empirical envelope curve. The largest relative deviation is found for $T_{\mathrm{X}}=500$ years. This can be explained by the fact that, $\mathrm{GEV}_{\text {bound }}$ is affected from $T_{\mathrm{X}}$ on also by the asymptotic behaviour and not only by the selection of $Q_{\text {PREC }}$.

In Fig. 10c, the largest deviation was estimated for the different $T_{\mathrm{X}}$ values when using the 95\%-quantile of $\mathrm{GEV}_{\text {sim-prec. The }} \mathrm{GEV}_{\text {sim-prec } 95}$ is higher skewed than $\mathrm{GEV}_{\text {sim-prec 05 }}$, because of the inclusion of larger $Q_{\text {PREC }}$ values. Thus, the difference between the two $\mathrm{GEV}_{\text {bound }}$ estimates with different $T_{\mathrm{X}}$ values is larger when using the $95 \%$ quantile due to the higher skewness. 

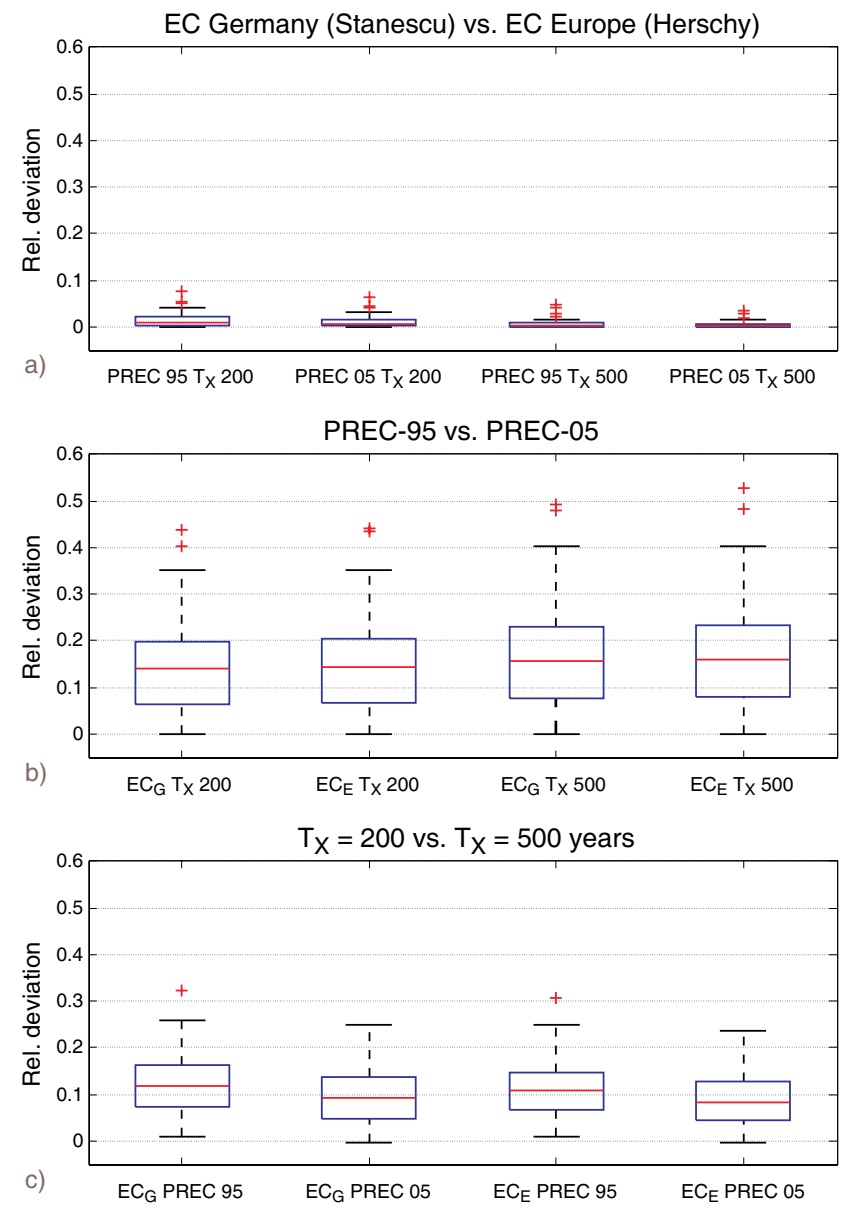

Fig. 10. Relative deviation between the quantile estimates of $\mathrm{GEV}_{\text {bound }}$ for $T=1000$ years when varying three choices. The boxplots show the results for the 76 sites which were used in the sensitivity analysis.

(a) Empirical envelope curves $\left(\mathrm{EC}_{\mathrm{G}}=\right.$ Germany; Stanescu, 2002; $\mathrm{EC}_{\mathrm{E}}=$ Europe; Herschy, 2002), (b) PREC flood discharges (95-, 5quantiles) and (c) inflection point $\left(T_{\mathrm{X}}\right)$.

The relative importance of the three choices is shown for all 76 gauges (Fig. 11). For each choice, the mean of the absolute relative deviation of the four approaches as indicated in Fig. 10 was estimated for each site separately. In a next step, the three mean absolute relative deviations were summed up (overall absolute relative deviation) and the fractions of the three choices were estimated. In this way, the importance of the three choices for all sites is given. The gauges are ordered by the distance between their unit floods of record and $E_{\mathrm{EC}}$. Figure 11 shows that the effect of the selection of the PREC flood discharges increases with larger distance to the REC, whereas the effect of the inflection point and of the empirical envelope curve decreases. This pattern can be explained when considering the three choices in detail.

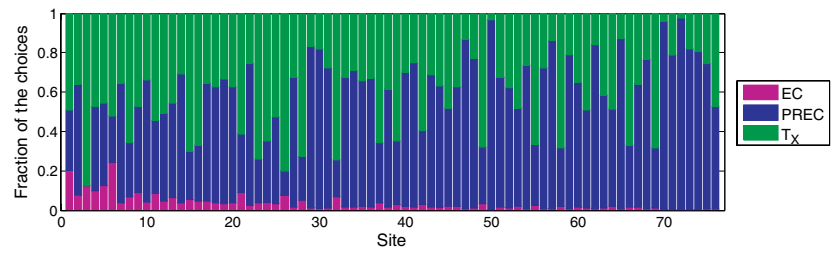

Fig. 11. Fraction of the three choices to the overall absolute relative deviation for each site in [\%]. The sites are ordered by the distance of the unit flood of record to the unit discharge of the European envelope curve.

$\mathrm{EC}=$ selection of the empirical envelope curve $\left(\mathrm{EC}_{\mathrm{G}}\right.$ vs. $\left.\mathrm{EC}_{\mathrm{E}}\right)$; $\mathrm{PREC}=$ selection of PREC flood discharges (95- vs. 5-quantiles); $T_{\mathrm{X}}=$ selection of the inflection point $\left(T_{\mathrm{X}}=200 \mathrm{vs}\right.$. 500 years $)$.

The effect of the choice of the empirical envelope curve considerably influences the discharge estimates for $T_{\mathrm{t}}$ only for sites with a small distance to the largest unit flood of record, i.e. the sites which are close to the empirical envelope curve. The closer they are to the European one, the larger is the fraction of the empirical envelope curve selection.

The intercept of a REC is defined by the largest standardised flood of record in the pooling group. The site which determines in all its PREC realisations the intercept of REC (Neundorf, site 9 in Fig. 1) has a relative deviation of zero related to the $Q_{\text {PREC }}$ selection (site 3 in Fig. 11), because $Q_{\text {PREC }}$ is always equal to the at-site flood of record. The smaller the at-site unit flood of record, the larger the distance to the largest unit flood of record of a pooling group could be within a REC. Because of that, the possible range of PREC discharges increases along with the distance between the atsite unit flood of record and the largest regional unit flood of record.

In addition, the effect of $T_{\mathrm{X}}$ is larger for sites with a high skewness. The larger the skewness, the larger are the differences between the discharge estimates for $T=200$ vs. $T=$ 500 years. Therefore, the influence of the choice of $T_{\mathrm{X}}$ also increases. Especially the sites with a large flood of record are characterised by a high skewness. Thus, the largest influence of the $T_{\mathrm{X}}$ selection is found for sites with floods of record close to EC. The fraction of the inflection point is highly correlated with the shape parameter $k$. The effect of the inflection point is negligible for sites with a small negative $k$, whereas its effect predominates when $k$ is highly negative.

\section{Discussion}

A novel method to integrate additional regional information about upper tail behaviour into at-site flood frequency analyses was presented. This study aimed at improving the discharge estimates for large $T$. The core ideas were to combine PREC flood quantiles with traditional flood frequency approaches and to introduce a mixed bounded distribution function which considers large flood quantiles as well as an upper 
bound discharge. It is interesting to compare this method with the integration of historical events, to discuss the selection of PREC flood quantiles and the results of the sensitivity analysis and to compare our procedure with traditional flood regionalisation methods.

There are some similarities between our method to integrate PREC flood quantiles and the use of historical floods as additional information in flood frequency studies. Historical floods are combined as non-systematic data with measured flood series. Generally, a threshold is fixed and the number of floods above this threshold in the historical period is determined (Stedinger and Cohn, 1986; Reis Jr. and Stedinger, 2005). The integration of historical information is based on the assumption that all extreme floods above the threshold are recorded because of the large amount of damages they have caused. However, in this approach discharge values are used only. The probabilities of the historic floods are unknown and are not considered (e.g. Martins and Stedinger, 2001). This is the largest difference to our method, which considers besides the discharge values also the recurrence interval of PRECs. Furthermore, whereas the use of historical data extends the time series, the integration of PREC flood quantiles is based on substituting the time period with spatial information. Because of that, a different approach than for the integration of historic data was chosen, which enabled us to use the additional information in terms of $T_{\mathrm{PREC}}$ and to integrate several $Q_{\text {PREC }}$ values.

The selection of the PREC flood quantiles is the most sensitive step for $T_{\mathrm{t}}$. The influence of the random process depends on two aspects. First, it is affected by the number of PREC realisations. The more PREC realisations, the more combinations of randomly selected PREC discharges are possible. Second, the results are influenced by the variation of the PREC flood quantiles in $Q_{\text {PREC }}$ as well as in its corresponding $T_{\text {PREC }}$. Small differences between the PREC flood quantiles lead to low differences in $\mathrm{GEV}_{\text {sim-prec }}$ independently of the number of PREC realisations.

The selection of the inflection point has the second largest effect. The inflection points were selected according to the aim of our study and the available data and PREC results. Based on the observed data, flood quantiles up to about 100 years can be estimated by at-site analysis. The recurrence interval of interest was 1000 years. Hence, we checked intermediate recurrence intervals as inflection point (200 and 500 years) to quantify the sensitivity of this choice. We finally selected an inflection point of 500 years, because the higher inflection point leads to a better consideration of the PREC flood quantiles. The larger the inflection point, the larger is the effect of the PREC flood quantiles.

As illustrated in Fig. 2, both empirical envelope curves differ strongly. However, the sensitivity analysis shows that the effect of the envelope curve selection on a discharge with $T=1000$ years is smaller than those of the random selection of PREC discharges or of the inflection point. In this context, it is worth noting that we predefined a target recurrence interval of 1000 years. Since the envelope curve governs the asymptotical approach towards the upper bound, the influence of the envelope curve selection will be larger for increasing $T$.

In traditional flood regionalisation approaches (e.g. index flood), the recurrence interval of interests can be increased successively by the inclusion of neighbouring data. Or, in other words, the uncertainty of large flood quantiles decreases with each added flood series that leads to a gain of information, and consequently, to an increase of the effective observation data. Our procedure differs from traditional methods, because it is based on two types of additional information (PREC flood quantiles and upper bound discharge) which are representative for specific parts of the distribution function. The target recurrence interval of 1000 years is covered by the PREC flood quantiles adequately. It is clear that we did not consider additional information to the at-site flood data for recurrence intervals smaller than the PREC flood quantiles (150 years). However, also the estimation of discharges with recurrence intervals smaller than 150 years might benefit from the use of PREC flood quantiles as additional information. A combination of our procedure with a traditional regionalisation approach could be a next step to increase the use of additional information.

\section{Conclusions}

A novel method to improve the quantile estimation for high recurrence intervals by using additional information was presented. Our study was focused on a recurrence interval of 1000 years. Large flood quantiles were derived by probabilistic regional envelope curves (PREC). These PREC flood quantiles were combined with the measured flood series. A mixed bounded distribution function was presented which considers in addition to the PREC flood quantiles also an upper bound discharge derived by an empirical envelope curve. The mixed bounded distribution function avoids an increase up to unrealistic large discharges. Whereas the combination of PREC discharges and a simulated flood series based on at-site parameters was used for recurrence intervals of up to 500 years, a bounded distribution function was applied for larger $T$.

The main outcomes of this study are:

1. The use of the additional information of PREC flood quantiles and empirical envelope curves supports the estimation of large quantiles.

2. The effect of PREC flood quantiles on the quantile estimation is especially relevant when the PREC discharge varies largely from the at-site GEV estimate for the same recurrence interval.

3. The sensitivity of the flood quantile of 1000 years to the selection of empirical envelope curves providing the 
upper bound discharge on a flood quantile of 1000 years is smaller than the selection of PREC flood quantiles and of the inflection point between both functions of the mixed bounded distribution.

Acknowledgements. This work is part of the Center for Disaster Management and Risk Reduction Technology (CEDIM) (http: //www.cedim.de), a joint venture between the Helmholtz Centre Potsdam - GFZ German Research Centre for Geosciences and the Karlsruhe Institute of Technology (KIT). We thank CEDIM and the GFZ for the financial support.

We thank the State Agency of Environment and Geology of the Free State of Saxony for the permission to use the discharge data. Furthermore we thank the State Agency for Environment of Thuringia for additional discharge data. We also thank the Federal Agency for Cartography and Geodesy of Germany (BKG) for the ATKIS-Basis-DLM and the digital elevation model for Saxony (BKG GeoDataCentre, 2005). The SRTM Digital Terrain Model was downloaded from (http://srtm.csi.cgiar.org/ SELECTION/inputCoord.asp, 19 May 2008) (Jarvis et al., 2008).

We gratefully acknowledge the very helpful advices from an anonymous referee and Attilio Castellarin in HESSD.

Edited by: H. Madsen

\section{References}

Benito, G., Lang, M., Barriendos, M., Llasat, M. C., Francés, F., Ouarda, T. B. M. J., Thorndycraft, V. R., Enzel, Y., Bárdossy, A., Coeur, D., and Bobée, B.: Use of Systematic, Palaeoflood and Historical Data for the Improvement of Flood Risk Estimation, Review of Scientific Methods, Nat. Hazards, 31(3), 623643, 2004.

BKG GeoDataCentre (Federal Agency for Cartography and Geodesy): Digital Landscape Model ATKIS Basis DLM, Frankfurt/Main, 2005.

Burn, D. H.: Evaluation of Regional Flood Frequency Analysis with a Region of Influence Approach, Water Resour. Res., 26(8), 2257-2265, 1990.

Castellarin, A.: Probabilistic envelope curves for design flood estimation at ungauged sites, Water Resour. Res., 43(4), W04406, doi:04410.01029/02005WR004384, 2007.

Castellarin, A., Vogel, R. M., and Matalas, N. C.: Probabilistic behaviour of a regional envelope curve, Water Resour. Res., 41, W06018, doi:06010.01029/02004WR003042, 2005.

Castellarin, A., Vogel, R. M., and Matalas, N. C.: Multivariate probabilistic regional envelopes of extreme floods, J. Hydrol., 336(34), 376-390, 2007.

Chbab, E. H., Buiteveld, H., and Diermanse, F.: Estimating exceedance frequencies of extreme river discharges using statistical methods and physically based approach, Österr. Wasser- und Abfallwirtschaft, 58(3-4), 35-43, 2006.

Cohn, T. A. and Stedinger, J. R.: Use of Historical Information in a Maximum Likelihood Framework, J. Hydrol., 96(1-4), 215-233, 1987.
Condie, R. and Lee, K. A.: Flood frequency analysis with historic information, J. Hydrol., 58(1-2), 47-61, 1982.

Costa, J. E.: A comparison of the largest rainfall-runoff floods in the United States with those of the People's Republic of China and the world, J. Hydrol., 96(1-4), 101-115, 1987.

Crippen, J. R.: Envelopes Curves for Extreme Flood Events, J. Hydraul. Eng.-ASCE, 108(8), 1208-1212, 1982.

Dalrymple, T.: Flood frequency analyses, US Geol. Surv. Water Supply Pap., 1543-A, 1960.

El Adlouni, S., Bobée, B., and Ouarda, T. B. M. J.: On the tails of extreme event distributions in hydrology, J. Hydrol., 355(1-4), 16-33, 2008.

England Jr., J. F., Jarrett, R. D., and Salas, J. D.: Data-based comparisons of moments estimators using historical and paleoflood data, J. Hydrol., 278(1-4), 172-196, $2003 \mathrm{a}$.

England Jr., J. F., Salas, J. D., and Jarrett, R. D.: Comparisons of two moments-based estimators that utilize historical and paleoflood data for the log Pearson type III distribution, Water Resour. Res., 39(7), 1243, doi:1210.1029/2002WR001791, 2003b.

Enzel, Y., Ely, L. L., House, P. K., Baker, V. R., and Webb, R. H.: Paleoflood evidence for a natural upper bound to flood magnitudes in the Colorado River basin, Water Resour. Res., 29(5), 2287-2298, 1993.

Fernandes, W. and Naghettini, M.: Integrated frequency analysis of extreme flood peaks and flood volumes using the regionalized quantiles of rainfall depths as auxiliary variables, J. Hydrol. Eng.-ASCE, 13(3), 171-179, 2008.

Fernandes, W., Naghettini, M., and Loschi, R.: A Bayesian approach for estimating extreme flood probabilities with upperbounded distribution functions, Stoch. Env. Res. Risk A., 24(8), 1127-1143, doi:10.1007/s00477-010-0365-4, 2010.

Francés, F.: Using the TCEV distribution function with systematic and non-systematic data in a regional flood frequency analysis, Stoch. Hydrol. Hydraul., 12(4), 267-283, 1998.

Francés, F. and Botero, B. A.: Probable maximum flood estimation using systematic and non-systematic information, in: Paleofloods, Historical Floods and Climatic Variability: Applications in Flood Risk Assessment, Proceedings of the PHEFRA workshop, edited by: Thorndycraft, V. R., Benito, G., Barriendos, M., and Llasat, M. C., Barcelona/Spain, 223-229, 2003.

Gaume, E., Bain, V., Bernardara, P., Newinger, O., Barbuc, M., Bateman, A., Blaskovicova, L., Blöschl, G., Borga, M., Dumitrescu, A., Daliakopoulos, I., Garcia, J., Irimescu, A., Kohnová, S., Koutroulis, A., Marchi, L., Matreata, S., Medina, V., Precisco, E., Sempere-Torres, D., Stancalie, G., Szolgay, J., Tsanis, I., Velasco, D., and Viglione, A.: A compilation of data on European flash floods, J. Hydrol., 367(1-2), 70-78, 2009.

Guillot, P. and Duband, D.: La méthode du gradex pour le calcul de la probabilité des crues à partir des pluies, Floods and Their Computation - Proceedings of the Leningrad Symposium, IAHS-AISH P., 84, 560-569, 1967.

Guse, B., Castellarin, A., Thieken, A. H., and Merz, B.: Effects of intersite dependence of nested catchment structures on probabilistic regional envelope curves, Hydrol. Earth Syst. Sci., 13, 1699-1712, doi:10.5194/hess-13-1699-2009, 2009.

Guse, B., Thieken, A. H., Castellarin, A., and Merz, B.: Deriving probabilistic regional envelope curves with two pooling methods, J. Hydrol., 380(1-2), 14-26, 2010. 
Gutknecht, D., Blöschl, G., Reszler, C., and Heindl, H.: A "MultiPillar"-Approach to the Estimation of Low Probability Design Floods, Österr. Wasser- und Abfallwirtschaft, 58(3-4), 44-50, 2006.

Herschy, R.: The world's maximum observed floods, Flow Meas. Instrum., 13, 231-235, 2002.

Hofherr, T., Kottmeier, C., Heneka, P., and Ruck, B.: Wintersturm Risiko Modell und Echtzeit-Schadensprognose, in: CEDIM Entwicklungsbericht Dezember 2008, edited by: CEDIM - Center for Disaster Management and Risk Reduction Technology, unpublished work, 17-19, 2008.

Hosking, J. R. M. and Wallis, J. R.: Paleoflood hydrology and flood frequency analysis, Water Resour. Res., 22(4), 543-550, 1986a.

Hosking, J. R. M. and Wallis, J. R.: The value of historical data in flood frequency analysis, Water Resour. Res., 22(4), 1606-1612, 1986b.

Hosking, J. R. M. and Wallis, J. R.: Some statistics useful in regional frequency analysis, J. Hydrol., 29(2), 271-281, 1993.

Hosking, J. R. M. and Wallis, J. R.: Regional frequency analysis: an approach based on L-moments, Cambridge University Press, Cambridge, UK, 1997.

Houghton-Carr, H.: Flood Estimation Handbook 4: Restatement and application of the Flood Studies Report rainfall-runoff method, Institute of Hydrology, Wallingford, UK, 1999.

Jarvis, A., Reuter, H. I., Nelson, A., and Guevara, E.: Hole-filled SRTM for the globe Version 4, available from the CGIARCSI SRTM 90 m Database, http://srtm.csi.cgiar.org, last access: 19 May, 2008.

Kanda, J. A.: A New Extreme Value Distribution With Lower and Upper Limits For Earthquake Motion and Wind Speeds, Theor. Appl., 31, 351-360, 1981.

Martins, E. S. and Stedinger, J. R.: Historical information in a generalized maximum likelihood framework with partial duration and annual maximum series, Water Resour. Res., 37(8), 25592567, 2001.

Merz, R. and Blöschl, G.: Flood frequency hydrology: 1. Temporal, spatial, and causal expansion of information, Water Resour. Res., 44, W08432, doi:08410.01029/02007WR006744, 2008a.

Merz, R. and Blöschl, G.: Flood frequency hydrology: 2. Combining data evidence, Water Resour. Res., 44, W08433, doi:08410.01029/02007WR006745, 2008b.

Merz, B. and Thieken, A. H.: Separating Natural and Epistemic Uncertainty in Flood Frequency Analysis, J. Hydrol., 309(1-4), 114-132, 2005.

Merz, B. and Thieken, A. H.: Flood risk curves and uncertainty bounds, Nat. Hazards, 51(3), 437-458, 2009.

Merz, R., Blöschl, G., and Humer, G.: National flood discharge mapping in Austria, Nat. Hazards, 46(1), 53-72, 2008.

Moon, Y.-I., Lall, U., and Boswarth, K.: A comparison of tail probability estimators for flood frequency analysis, J. Hydrol., 151(24), 343-363, 1993.

Naghettini, M., Potter, K. W., and Illangasekare, T.: Estimating the Upper Tail of Flood-Peak Frequency Distributions Using Hydrometeorological Information, Water Resour. Res., 32(4), 1729-1740, 1996.
Peel, M. C., Wang, Q. J., Vogel, R. M., and McMahon, T. A.: The Utility of L-moment ratio Diagrams for selecting a regional probability distribution, Hydrolog. Sci. J., 46(1), 147-156, 2001.

Petrow, Th., Thieken, A. H., Kreibich, H., Bahlburg, C. H., and Merz, B.: Improvements on flood alleviation in Germany: Lessons learned from the Elbe flood in August 2002, Environ. Manage., 38(3), 717-732, 2006.

Petrow, Th., Merz, B., Lindenschmidt, K.-E., and Thieken, A. H.: Aspects of seasonality and flood generating circulation patterns in a mountainous catchment in south-eastern Germany, Hydrol. Earth Syst. Sci., 11, 1455-1468, doi:10.5194/hess-11-14552007, 2007.

Pohl, R.: Historische Hochwasser aus dem Erzgebirge, Fakultät Bauingenieurwesen, Institut für Wasserbau und Technische Hydromechanik, Technische Universität Dresden, Dresden Wasserbauliche Mitteilungen, Heft 28, 2004.

Reis Jr., D. S. and Stedinger, J. R.: Bayesian MCMC flood frequency analysis with historical information, J. Hydrol., 313(12), 97-116, 2005.

Robson, A. and Reed, D.: Flood Estimation Handbook 3: Statistical procedures of flood frequency estimation, Institute of Hydrology, Wallingford, UK, 338 pp., 1999.

Rossi, F., Fiorentino, M., and Versace, P.: Two component extreme value distribution for flood frequency analysis, Water Resour. Res., 20(5), 847-856, 1984.

Schumann, A. H.: Das hydrologische Risiko bei der Bemessung und der Bewirtschaftungsplanung von Talsperren, Wasserbauliche Mitteilungen, Heft 27, 33-46, 2004.

Schumann, A. H.: Flood statistical assessment of the event from August 2002 in the Mulde river basin, based on seasonal statistics, in German: Hochwasserstatistische Bewertung des Augusthochwassers 2002 im Einzugsgebiet der Mulde unter Anwendung der saisonalen Statistik, Hydrol. Wasserbewirts., 49, 200-206, 2005.

Stanescu, V. A.: Outstanding floods in Europe, A regionalization and comparison, International Conference on Flood Estimation, Berne, Switzerland, 697-706, 2002.

Stedinger, J. R. and Cohn, T. A.: Flood frequency analysis with historical and paleoflood information, Water Resour. Res., 22(3), 785-793, 1986.

Stedinger, J. R., Vogel, R. M., and Foufoula-Georgiou, E.: Frequency Analysis of extreme events, in: Handbook of Hydrology, edited by: Maidment, D. A., McGraw-Hill, New York, 18.1118.66, 1993.

Thieken, A. H., Müller, M., Kreibich, H., and Merz, B.: Flood damage and influencing factors: New insights from the $\mathrm{Au}-$ gust 2002 flood in Germany, Water Resour. Res., 41(12), W12430, doi:101029/102005WR004177, 2005.

Ulbrich, U., Brücher, T., Fink, A. H., Leckebusch, G. C., Krüger, A., and Pinto, J. G.: The central European floods of August 2002: part 1 - Rainfall periods and flood development, Weather, 58(8), 371-377, 2003.

Vogel, R. M. and Fennessey, N. M.: L-moments diagrams should replace product moment diagrams, Water Resour. Res., 29(4), 1745-1752, 1993. 